\title{
Pedagogical concerns and challenges of Education for Sustainable Development
}

\author{
Dr. Manjula P. Rao, \\ Professor Department of Education Regional Institute of Education (NCERT) Mysore-Karnataka, India
}

\begin{abstract}
Global environment and ecology are rapidly becoming the demanding subjects of discussions necessitating decision and action in the required direction as the environmental problems have emerged due to exploitation of natural resources for want of basic needs and so called the developmental measures. The developed and the developing countries share the environmental concerns alike which have their roots in societal, economical and ecological bases. Therefore, Sustainable Development is grounded on four independent systems such as bio-physical, economic, social and political. It supports interrelated principles such as peace, equity, democracy, appropriate development and conservation for sustainable living. Education has been acknowledged worldwide as a fundamental tool and one of the major means of sustaining the resources and its judicious utility, so that the earth resources could be protected for future generations. Education for Sustainable Development (ESD) is an emerging concept that seeks to empower people of all ages in the world to assume responsibility for creating a sustainable future. The role of education is the major determinant in increasing creativity, rationality, problem-solving abilities, critical and analytical mindedness needed to foster the increasingly complex cultural, social and technological decisions involved in sustainable development. This paper examines some of the above critical concerns and issues related to sustainable development. It highlights the need for an interdisciplinary and a holistic approach to ESD in school education which is value driven, future and action oriented in nature. It attempts to discuss an across-the-curriculum approach to education for a sustainable future and the pedagogic concerns required to examine the local as well as global issues related to sustainable development.
\end{abstract}

\section{Introduction}

All of us are aware of the fact that our earth planet is rich with thousands and thousands of species, and plenty of natural resources. This extraordinary richness of life that surrounds us in the form of diverse arrays of organisms, ecological communities, and natural landscapes sustain human activities such as agriculture, forestry, fisheries etc, are the basis of our civilization. The natural resources that support our lives have been in existence since billions of years. This biodiversity and mineral rich environment, a product of billion years of evolution, has been rapidly declining in recent years, as a victim of explosion of human population, increasing human needs and demands, and ever expanding technology and industry in the name of development. Because of the environmental problems which are rapid and devastating, the global environment and ecology have become the most demanding subjects of discussion, thereby necessitating proper decisions and actions in the required direction.

We also see all over the world that, the development has resulted in disparities in terms of socioeconomic conditions between rich and poor countries. History has revealed to us, the vast inequalities, showing almost three-fourths of the world's people living in less-developed countries and one-fifth below the poverty line. The long-term impact of post industrialization, exploitation and environmental damage cannot be overlooked. It is only right that development in this new century be even more conscious of long term impact of industrialization. Our common future can only be achieved with a better understanding of our common concerns and shared responsibilities. The concepts of interrelatedness, of a shared planet, of global citizenship, and of 'spaceship earth' cannot be restricted to environmental issues alone. They apply equally to the shared and inter-linked responsibilities of environmental protection and human development. It is evident through times that there have been multiple cases of development failures, whose roots were not linked to constraints in utilization of natural resources. Though there have been major efforts at the international and national levels to promote sustainable future, education has been considered as a prerequisite for achieving sustainable development and an essential tool for good governance at both state, national and at international levels. Therefore, a need emerges for a paradigm shift in education which encompasses the necessity for developing a concern and awareness towards sustainable development in the present and for the future. This paper highlights the need for sustainable development and its education among the masses, especially among the school going youth who are the future generations. The aims and the perspectives of education for sustainable development and the related pedagogic concerns are discussed with a focus on the challenges and the issues associated. 


\section{Need for sustainable development - Global scenario}

The goal of sustainable development is to improve living standards and the quality of human lives, both now and for future generations. Some of the environmental issues which are the important challenges of development are discussed here.

At the global level, acid rain, desertification, global warming, ozone layer depletion, pollution, radiation and species extinction are some of the most urgent environmental problems. Some environmental issues are highly localized, while many others cross national borders. For instance, the Industrial and human waste dumped into rivers of one country affect the health and livelihoods of citizens of another country. Global environment and ecology are the most demanding subjects of discussion today necessitating decision and action in the required direction. We see that efforts at the global level are concentrated to forge international cooperation in tackling these problems. The boom in global consumption over the past decade has been accompanied by improvement in living standards in many countries and decline in others. In some of the parts of the world, the poverty is on the rise and a large number of people do not have sufficient land to grow the food and access to the growing consumption of resources. In African countries, such as Kenya, Zambia and Zimbabwe, around $40 \%$ of the population is malnourished

Forests are resource centres for extremely diverse biological communities, producing variety of forest products. They are considered to be living treasure houses with uncounted habitats and species which are diverse in nature and as carbon sinks of the world, but the world wide loss of forests is alarming. Large forest area in temperate regions of Europe, North America, North Africa and Asia are being cut for the past more than hundred years. A report by the Food and Agriculture Organization shows an estimated annual loss of some 11.3 million hectares of forests worldwide. In India, the good forest cover is estimated to be just $11 \%$ against the desirable $33 \%$ of the total land area as per the National Forest policy. It is observed that biodiversity throughout the world is declining, and more so in India, due to expanding human populations, increasing consumption, growing trade in natural products, misguided policies and poor governance. How do we conserve biodiversity in a country with more than one billion people and aspirations of an annual economic growth rate of 9-10 percent? Biodiversity is threatened not only by demographic and developmental pressures, but also by climatic change. All these pressures are likely to intensify in the immediate future. It is estimated that if the current deforestation trend continues, then, as many as $25 \%$ of all species inhabited the earth in the mid 1980's will disappear by 2015. Wild scale deforestation contributes to the greenhouse effect and soil erosion which consequently makes the lowland areas more vulnerable to flooding. A report by an Inter-governmental panel on climatic changes (IPCC) warns of climate change due to global warming with devastating effect on millions of people, animals and plants. It is learnt that before industrial revolution, carbon dioxide concentration was around 280 parts per million (ppm). But today, it is about $360 \mathrm{ppm}$ and is increasing at about $1.2 \mathrm{ppm}$ every year. Along with carbondioxide, other GHGs are being added to earth's atmosphere at accelerating rates. It is estimated that by 2035 A.D, the continuing GHG accumulations at current rate will result in an increase in average temperature of 1.5 to 4.5 degrees centigrade for the earth as a whole which may have a great impact on the humans and the environment. The problem of $\mathrm{CO}_{2}$ emissions is a major concern to the Indian energy sector where coal accounts for over $60 \%$ of total energy resources used. India is ranked fifth in the world with respect to $\mathrm{CO}_{2}$ emission behind the United States, China, Russia and Japan. India's contribution to world carbon emission is expected to increase in coming years at an estimated average annual growth rate of $3.2 \%$ by 2020 ; comparatively it is $3.9 \%$ in China and $1.3 \%$ in the United States.

Fresh water is one of the most important substances for sustaining human life. Although it is a renewable resource, only $3 \%$ of earth's water supply is fresh. About $90 \%$ of the world's population gets its water supplies from river basins. More than 200 rivers are shared by two or more countries and more than $40 \%$ of the world's population relies on water originating in a country other than their own. Despite its availability, water is not evenly distributed or used around the world. More than 1.2 billion people do not have access to adequate and safe water supplies. Six of the 20 major river basins in India suffer from water scarcity. Water has already become one of the most limiting resources in the country.

An awareness of the above prevailing dangerous situations of earth has led many scientists across the world in predicting the calamities that could happen to the earth if man's affectations continue to expand. Various measures were planned and adopted to some extent, though not successfully, to control the environmental devastation at the international and National levels.

From the above situations, it is evident that, protection and conservation of earth is utmost important a task, the role of human beings in sustaining the earth and its resources and human beings entitled to a healthy and productive life in harmony with nature. All countries of the world have the essential task of eradicating poverty as an indispensable requirement for sustainable development in order to decrease the disparities in standards of living and meet the basic needs and requirements of the majority of people of today as well as of future. 
In order to bring about awareness and to maintain the balance of the ecosystem, the developing countries had started giving more emphasis to the concept of Sustainable development and its education in formal educational settings as well as in non-formal settings to the student population as well as to the other community members.

\section{Sustainable Development}

One of the original descriptions of sustainable development is credited to the Brundtland Commission according to which "Sustainable development is development that meets the needs of the present without compromising the ability of future generations to meet their own needs" (World Commission on Environment and Development, 1987, p 43). Sustainable development is generally thought to have three components: environment, society, and economy which are interrelated and influence each other focusing on principles of social equity and on the ecological constraints posed by the planet to economic and demographic growth.

From the above meaning, we can say that, sustainability is a paradigm for thinking about a future in which environmental, societal, and economic considerations are balanced in the pursuit of development and improved quality of life. It rejects the contention that casualties in the environmental and social realms are inevitable and acceptable consequences of economic development. There are a number of conflicting opinions and questions related to this. Some of the questions are- can the long-term economic objective of sustained agricultural growth be met if the ecological objective of preserving biodiversity is not? What happens to the environment and its resources in the long term, if the over populated human species cannot afford to meet their basic needs today? If one does not balance social, economic and environmental objectives in the short term, how can we expect to sustain development in the long term? and so on. Sustainable development suggests that meeting the needs of the future depends on how well we balance social, economic, and environmental needs, when making decisions today. The consensus of United Nations Conference on Environment and Development (UNCED) in 1992 made clear that, just as there can be no future if the natural environment- the material base of life- is destroyed, so there can be no future for humanity, if it is diminished by poverty, illness, ignorance or tyranny.

Sustainable development establishes linkages across poverty alleviation, human rights, peace and security, cultural diversity, biodiversity, food security, clean water and sanitation, renewable energy, preservation of the environment and the sustainable use of natural resources. One of the principles laid down by the Agenda 21, the Rio Declaration of Environment and Development, states that the development of today must not undermine the developmental and environmental needs of present and future generations. This view of sustainable development seeks to ensure a better quality of life for everyone now and for the generations to come. Hence, a fundamental principle in learning for sustainable development is the idea of each individual's involvement, responsibility and commitment to local and global discussions on our common future, which gives democracy a central role.

Besides the developmental projects and the measures that are adopted at national and international levels to control the issues and problems that were detrimental to sustainability of environment, education is considered to be one of the important measures to create awareness among people in the formal as well as in the informal and non-formal education contexts. All these decades, the environmental concepts and issues were treated under the area 'Environmental Education' which is included in the Higher education courses and in the school education either as a separate subject or as an integrated part of other school subject areas with the objectives of creating awareness about environmental matters and to develop proper attitudes and values towards conserving environment. Of late environmental education is increasingly becoming education for sustainable development or sustainable future within a vision of society and of education that considers change and attention to social and environmental emergencies as the key for its development. It acknowledges that the planet, the environment, society and mankind can continue to live only through change, by evolving, in order to take emergent situations into account.

\section{Education for sustainable development (ESD)}

Education for sustainable development is more than a knowledge base related to environment, economy and society. It also addresses learning skills, perspectives and values that guide and motivate people to seek sustainable livelihoods, participate in a democratic society and live in a sustainable manner. Education for Sustainable Development was first described by Chapter 36 of Agenda 21, which identified reorienting existing education to address sustainable development as one of its four major thrusts. The outcomes of the "World Summit on Sustainable Development" (Johannesburg, 2002) underpin the need to integrate sustainable development into education system at all levels of education, in order to promote education as a key agent for change. The summit also recommended the adoption of the Decade on education for sustainable development by the UN General Assembly (2005). 
The main aim of education for a sustainable development becomes education for global citizenship throughout one's life in order to build a knowledge society in which it is the local community that, within a bottom-up participated process, acknowledges the necessary and possible changes. Based on the core principle of sustainable development, we can say that, ESD involves integrating knowledge of economic, social and environmental development. It provides opportunities for learners to participate in democratic discussions about what is important to them personally, and for society in the future. It also develops and strengthens the capacity of individuals, groups, communities, organizations and countries to make judgments and choices thus aiming at making our world safer, healthier and more prosperous, thereby improving the quality of life. It includes processes such as critical reflection, greater awareness and empowerment so that new visions and concepts can be explored and new methods and tools can be developed. ESD increases the civil capacity by enhancing and improving the workforce, social tolerance, environmental stewardship, participation in community- based decision making which should be enhanced by all sectors of education. An attitude of concern for the quality of the environment is important to motivate people to develop skills, willingness to take necessary decisions and actions for solving environmental problems. Thus education becomes an indispensable element for achieving sustainable development.

Education for Sustainable Development is based on ideals and principles that underlie sustainability such as intergenerational equity, gender equity, social tolerance, poverty alleviation, environmental preservation and restoration. This is stated in Rio Declaration which consists of 27 principles of sustainability, among which some of them that reflect the above are i) People are entitled to a healthy and productive life in harmony with nature ii) The right to development must be fulfilled so as to equitably meet developmental and environmental needs of present and future generations, and iii) Eradicating poverty and reducing disparities in living standards in different parts of the world are essential to sustainable development (Keating, 1993). These principles help governments, communities and school systems to identify knowledge, principles, skills and values on which they will create Education for sustainable development or reorient existing education to address sustainability.

\section{Pedagogic concerns and challenges of Education for Sustainable Development}

Educating for the type of changes as envisioned in the Rio Declaration and Agenda 21, is a challenge to schools, especially in the integrated manner with the other school subjects. The National Curriculum frameworks for school education developed by the NCERT in 1988, 2000 and 2005, have consistently reiterated the concept of protection of environment as one of the major core components of school curriculum that needs to be reflected in school subjects. Considering the present shift in understanding the learner and the learning process, from the behaviouristic to the constructivistic, the education for sustainable development can no longer remain a matter of knowledge and information transmission, but a process of actively constructing meanings in social setups, along with development of required skills and values. Knowledge of this kind cannot be considered as separate from the community and from the surrounding territory, but one should try to jointly build relevant knowledge for that community and that particular context, to work on 'open issues', by encouraging the school community and local community to explore together. Above all, it is a matter of becoming aware of our ways of perceiving our planet, and to consider ourselves in relation to the planet, in order to strengthen or modify our behaviours and our thoughts in the direction of learning to 'live the Earth wisely' (Mortari, 1994). Learning to think differently also means taking on the responsibility for our thoughts, of the contribution they can make to a future still to be built. School education must be reoriented to address sustainability and expanded to include critical-thinking skills, skills to organize and interpret data and information, skills to formulate questions, and the ability to analyze issues that confront communities.

For a successful implementation of ESD, it must have an impetus from national or regional governments that drive policy development. There is a need to include ESD as a priority area in the educational policies of the country followed by necessary directives and frameworks for practice in the system. The Ethical issues and concerns of sustainable development need to be addressed through education at different levels to make an impact on people's lifestyles and responsible behaviours and help them build a sustainable future. A need to refocus many existing educational policies, programmes and the curriculum of school education to emphasize ESD issues is mandatory, as education can play a very significant role in ensuring the economic, cultural and ecological vitality of the growing human world communities. A systemic approach is required in the planning, implementation and monitoring of ESD in all contexts of education- formal and non-formal.

Reorienting existing school and higher education to address sustainability poses many challenges such as reorganization of existing curriculum: capacity building of educators, and adopting innovative approaches in initiating learners into the knowledge, skills, perspectives, and values that will guide and motivate learners to pursue sustainable livelihoods, to participate in a democratic society, and to live in a sustainable manner. Usually, it is thought that the concepts and issues related to environment and sustainability belong to the realm of science and social science disciplines. It is important to realize that no one discipline can or should claim ownership of ESD. In fact, ESD poses such broad and encompassing challenges that it requires contributions 
from many disciplines. The synergistic strengths of combined educational disciplines can convey the knowledge, issues, skills, perceptions, and values associated with ESD. The United Nations Division for Sustainable Development has listed several areas that come within the scope of sustainable development such as agriculture, atmosphere, biodiversity, biotechnology, climate Change, consumption and production Patterns, demographics, energy, forests, Fresh Water etc. Many topics inherent in ESD are already a part of the formal school curriculum, but these topics do not seem to be contributing to the larger concept of sustainability, as they are treated as mere subject matter to be mastered. Identifying and recognizing the scope for integrating the concepts, issues and values of ESD in the existing curriculum is not only challenging, but also imperative to progress towards sustainable future.

To create and support ESD initiatives will require properly trained administrators, educators, curriculum developers, and evaluators. It is necessary to ensure that educators and administrators understand the concept of sustainability and are familiar with its principles before they initiate their learners into ESD. There is a need to provide learners for practical and application skills which are contextual and problem based that will enable them to continue learning even after they leave school, to have a sustainable livelihood, and to live sustainable lives. One of the objectives of ESD is to develop an understanding of global issues as well as local issues in a global context. Every issue has a history and a future. Analyzing the roots of an issue and forecasting possible futures based on different contexts becomes a critical function of ESD.

Devising new ways of organizing education processes using all the potential education resources of the society is an important pedagogic concern of ESD. Introducing the learners to education for sustainability through new pedagogic approaches and methods enable them to become more critical, analytical and reflective in their approach to understanding of sustainability. Since the main objective of ESD is to create an awareness of sustainable development, positive attitude and skills and decision making abilities, the learning approach to ESD could involve, introduction of a real-life problem related to sustainable development for the students to resolve. There is a need for learner-centered environment facilitated by the teachers. Contextualizing learning through real life episodes, case histories, and illustrations; exploring the environment and interacting with the community around to seek data, interpreting and analyzing the data and draw conclusions are some of the ways through which the awareness related to the need for sustainable development could be developed. A productive group interaction during the learning process where the students share their ideas and experiences, discuss freely, negotiate each others' ideas and arrive at a consensus to the solution of a problem related to sustainable developmental issues could be encouraged. The students may be encouraged to reflect on their experiences and procure evidences; examine critically their own roles in sustaining the resources and reflect on their own values, and values of others in order to clarify and prioritize their own values related to sustainable development. Action-oriented teaching and learning process should be emphasized in ESD, so that the students develop required competences to undertake actions and to facilitate sustainable changes in the short and long run. Critical thinking which include higher cognitive skills - logical analysis of situations and contexts, arriving at logical conclusions, making judgements, ascertaining, decision making, logical reasoning and inquiry needs to be developed with reference to the issues and problems of sustainable development. It is obvious that the teacher's role in such an endeavour is crucial.

Finally, what is crucial for a teacher of sustainable development is to place the ethics of sustainability as the core of his/her teaching and practice. Seeking to educate for sustainable development requires teachers to inspire and encourage a commitment to the values of social justice, equity, peace, ecological integrity, democratic values and respect to nature and concern for earth's resources. It is required that educators of sustainable development themselves should reflect these commitments and values in their daily life practices in order to be right models to the students and the community around. To successfully implement ESD, governments and school districts must plan ahead and develop strategies to address the issues of sustainable development. These issues should be addressed at every level, especially at the national level, to ensure consistent implementation of ESD across the country.

\section{Conclusion}

Normally, education aims to prepare persons for individual development in the developing society and to take rightful place in the society and for life and work in society as it is. Education for sustainable development prepares one, constructively, to deal with basic scarcity of resources in modern times and novel ways of thinking and acting for sustainable future. While sustainable development is a long term goal for human society, and a process that necessarily needs long time and effort, there is a sense of urgency to make the progress quickly. The contemporary problems related to natural resource management and a need for education for sustainable development call for the meaningful participation of the community and all concerned stakeholders in education. Education for sustainable development which is crisis-conscious and crisis-oriented education represents a new phenomenon in pedagogical history. It is hoped that the developmental efforts to sustain the resources on the earth along with proper educative measures to change the perspectives and the 
attitudes of human beings in a desired direction would be worthwhile activities in a march towards sustainable future.

\section{References}

[1]. Arvind Kumar (2003) "Environmental challenges of the $21^{\text {st }}$ century", APH Publishing Corporation, New Delhi.

[2]. Jackson M.G, (2001) "Effective Environmental education needs 'New Science", Indian Educational review, 37(2), pp 22-38.

[3]. Rao, Manjula (2013) "Education for Sustainable Development- a source book for teachers", Regional Institute of Education (NCERT), Mysore.

[4]. UN Resolution 57/254 UN General Assembly, 57'session, 2002

[5]. UNESCO (1997) "Educating for a Sustainable Future: A Transdisciplinary Vision for Concerted Action", Paris

[6]. UNECE (2003) "Basic elements for the UNECE strategy for Education for sustainable development" UNECE $5^{\text {th }}$ Ministerial Conference "Environment for Europe" Kiev, 21-23 May 2003.

[7]. UNESCO (1980)" Environmental Education in the light of the Tbilisi Conference", Paris.

[8]. UNESCO (2001) "Teaching and Learning for a sustainable Future", Paris.

[9]. UNESCO (2002) "Education for sustainability, From RIO to Johannesburg: Lessons learnt form a decade of commitment”, Paris.

\section{Websites}

[10]. A RIO Declaration (1992) Agenda 21-Chapter 36: promoting Education, Public awareness and training. http://habitat.egc.org/agenda21/

[11]. Brundtland Commission (1987). http://en.wikipaedia.org/wik/Brundtland Commission/

[12]. The Johannesburg World Summit on Sustainable Development (WSSD,2002). http://www.issd.ca/wssd/

[13]. UNESCO (1992) Earth Summit. http://www.earthcharter.inaction.org/

[14]. UNESCO(1997)Educating for sustainable future: A trans disciplinary vision for concerted action. http://www.unesco.org/education/tisf

[15]. HUNECE: http://www.unece.org

[16]. UN Division for Sustainable Development: http://www.un.org/esa/sustdev

[17]. UNESCO; http://www.unesco.org 